ARTICLE

https://doi.org/10.1038/s41467-019-08644-w

\title{
Block copolymer derived uniform mesopores enable ultrafast electron and ion transport at high mass loadings
}

Tianyu Liu (i) ${ }^{1}$, Zhengping Zhou', Yichen Guo ${ }^{1}$, Dong Guo ${ }^{1}$ \& Guoliang Liu (1) 1,2,3

High mass loading and fast charge transport are two crucial but often mutually exclusive characteristics of pseudocapacitors. On conventional carbon supports, high mass loadings inevitably lead to sluggish electron conduction and ion diffusion due to thick pseudocapacitive layers and clogged pores. Here we present a design principle of carbon supports, utilizing self-assembly and microphase-separation of block copolymers. We synthesize porous carbon fibers (PCFs) with uniform mesopores of $11.7 \mathrm{~nm}$, which are partially filled with $\mathrm{MnO}_{2}$ of $<2$ $\mathrm{nm}$ in thickness. The uniform mesopores and ultrathin $\mathrm{MnO}_{2}$ enable fast electron/ion transport comparable to electrical-double-layer-capacitive carbons. At mass loadings approaching $7 \mathrm{mg} \mathrm{cm}^{-2}$, the gravimetric and areal capacitances of $\mathrm{MnO}_{2}(\sim 50 \%$ of total mass) reach $1148 \mathrm{~F} \mathrm{~g}^{-1}$ and $3141 \mathrm{mF} \mathrm{cm}{ }^{-2}$, respectively. Our $\mathrm{MnO}_{2}$-coated PCFs outperform other $\mathrm{MnO}_{2}$-based electrodes at similar loadings, highlighting the great promise of block copolymers for designing PCF supports for electrochemical applications.

\footnotetext{
${ }^{1}$ Department of Chemistry, Virginia Tech, Blacksburg, VA 24061, USA. ${ }^{2}$ Macromolecules Innovation Institute, Virginia Tech, Blacksburg, VA 24061 USA. ${ }^{3}$ Division of Nanoscience, Virginia Tech, Blacksburg, VA 24061, USA. Correspondence and requests for materials should be addressed to G.L. (email: gliu1@vt.edu)
} 
H igh mass loading and fast charge transport are at the heart of electrochemical energy storage ${ }^{1-3}$. The former is crucial for high energy per device, and the latter for high power ${ }^{4}$. Low-cost, high-capacitance, and environment-benign pseudocapacitive $\mathrm{MnO}_{2}$ are loaded on electrically conductive supports and used as supercapacitor electrodes with a theoretical limit of $1367 \mathrm{~F} \mathrm{~g}^{-1}$ (based on a potential window of $\left.0.8 \mathrm{~V}\right)^{5-9}$. Toward commercialization, the mass loading of the total active materials must be at least $5 \mathrm{mg} \mathrm{cm}^{-210}$. However, high mass loadings often lead to thick and dense layers of insulating $\mathrm{MnO}_{2}$ $\left(10^{-5} \sim 10^{-6} \mathrm{~S} \mathrm{~cm}^{-1}\right)$ on the supports ${ }^{1-14}$. Consequently, the internal resistance increases and the ion diffusion is perturbed, resulting in sluggish charge transport-both electron conduction and ion diffusion ${ }^{5,11,15}$. Here we innovate the design of porous carbon fiber (PCF) as a lightweight, flexible, binder-free, and conductive-additive-free support for $\mathrm{MnO}_{2}$. Using the disparate concept of block copolymer microphase-separation to generate uniform mesopores in PCFs, we have bridged the two mutually exclusive characteristics, i.e., high mass loadings and ultrafast electron/ion transport.

An ideal support for $\mathrm{MnO}_{2}$ and other transition metal oxides $\left(\mathrm{RuO}_{2}, \mathrm{NiO}, \mathrm{WO}_{3}\right.$, and $\mathrm{Fe}_{2} \mathrm{O}_{3}$, etc.) needs the characteristics of (1) lightweight, (2) large surface areas for high loadings, (3) high electron conductivity, and (4) low ion diffusion resistivity. However, there is not a single nanostructure that meets all these characteristics $^{5,15}$. Carbon supports are inherently lightweight and electrically conductive. At high mass loadings of transition metal oxides, the electrical conductivity of electrodes decreases, but it can be restored by blending or wrapping with additional conjugated polymers ${ }^{16,17}$ or carbon additives ${ }^{16,18,19}$, as shown for excellent supports such as wearable textile structures ${ }^{16}$ and graphene ${ }^{16,20}$. The ion conduction, however, is drastically complicated $^{21}$, and the efficient ion diffusion across the entire support, as well as the thick layer of $\mathrm{MnO}_{2}$, remains a significant challenge. To mitigate the ion diffusion resistivity, ultrathin layers of $\mathrm{MnO}_{2}$ have been deposited on model supports, e.g., nanoporous $\mathrm{Au}^{22,23}$, Pt foil ${ }^{9}, \mathrm{Ni}$ foil ${ }^{24}, \mathrm{Si}$ wafer ${ }^{25}$, dendritic $\mathrm{Ni}^{26}$ and macroporous $\mathrm{Ni}$ film ${ }^{27}$. With a thickness of $<10 \mathrm{~nm}^{22}$ or at a mass loading of $<0.35 \mathrm{mg} \mathrm{cm}^{-2}$ on the model supports ${ }^{23,26}, \mathrm{MnO}_{2}$ exhibits fast electron/ion transport and the gravimetric capacitances approach the theoretical limit. Nevertheless, when the conventional lightweight carbon supports are loaded with $\mathrm{MnO}_{2}$, they either suffer from a limited surface area for depositing a large amount of $\mathrm{MnO}_{2}$ thin layers (e.g., carbon cloth ${ }^{11,12}$, carbon fibers ${ }^{16,28-30}$ and other macroporous carbons ${ }^{13,14}$ ), or they lack desirable porous structures that facilitate rapid ion diffusion across long distances to maintain high rate capability (e.g., microporous carbons ${ }^{5,15,31}$ ).
Ultimately the key to high mass loading and fast electron/ion transport lies at the design of porous carbon architectures ${ }^{32,33}$. We hypothesize that mesoporous carbon fibers with a narrow pore size distribution are the most preferable for addressing the challenges of high mass loading and fast electron/ion transport. Conversely, micropores are susceptible to clogging after loading with $\mathrm{MnO}_{2}$ and thus provide sluggish ion transport, while macropores offer limited surface areas for high mass loadings of transition metal oxides. In addition, non-uniform mesopores lead to inefficient use of the surface area for depositing $\mathrm{MnO}_{2}$ and potential clogging of the small pores.

To test our hypothesis, herein we demonstrate block copolymer-derived PCFs as lightweight and high mass-loading supports for $\mathrm{MnO}_{2}$ (Fig. 1). Because block copolymers selfassemble and microphase separate into uniform and continuous nanoscale domains ${ }^{34-41}$, after pyrolysis they generate interconnected mesoporous carbons with large surface areas for depositing $\mathrm{MnO}_{2}$. Disparate from all other carbon supports, the mesopores are designed from the macromolecular level and offer a high degree of uniformity. Importantly, our judiciously designed mesopores have an average diameter of $11.7 \mathrm{~nm}$ and are partially filled with a $<2$-nm-thick layer of $\mathrm{MnO}_{2}$ (Fig. 1c). On the one hand, the remaining mesopores provide continuous channels for efficient ion transport across the entire electrode, significantly reducing the ion diffusion resistance. On the other hand, the fibrous carbon network provides expressways for efficient electron transport without the need for any conductive additives. This contrasts with hard-templated mesoporous carbon particulates (e.g., $\mathrm{CMK}-3^{31}$ ), which demand polymer binders to hold the discrete carbon particulates together. At high mass loadings approaching $7 \mathrm{mg} \mathrm{cm}^{-2}$, the $\mathrm{PCF}$-supported $\mathrm{MnO}_{2}$ electrodes $\left(\mathrm{PCF} @ \mathrm{MnO}_{2}\right)$ show superior electron/ion transport and outstanding charge-storage performances.

\section{Results}

Morphology. To illustrate the crucial importance of uniform mesopores for high mass loading of $\mathrm{MnO}_{2}$, we have synthesized two types of carbon fibers, i.e., PCFs with uniform mesopores derived from poly(acrylonitrile-block-methyl methacrylate) (PAN-b-PMMA) and conventional carbon fibers (CFs) with limited mesopores from pure polyacrylonitrile (PAN). Scanning electron microscopy (SEM) shows the contrasting morphologies of PCFs and CFs (Fig. 2a, d and Supplementary Fig. 1). Owing to the microphase separation of PAN-b-PMMA and the subsequent degradation of poly(methyl methacrylate) (PMMA), the PCFs were perforated with a large number of uniformly distributed, randomly oriented, and interconnected mesopores of $\sim 11.7 \mathrm{~nm}$

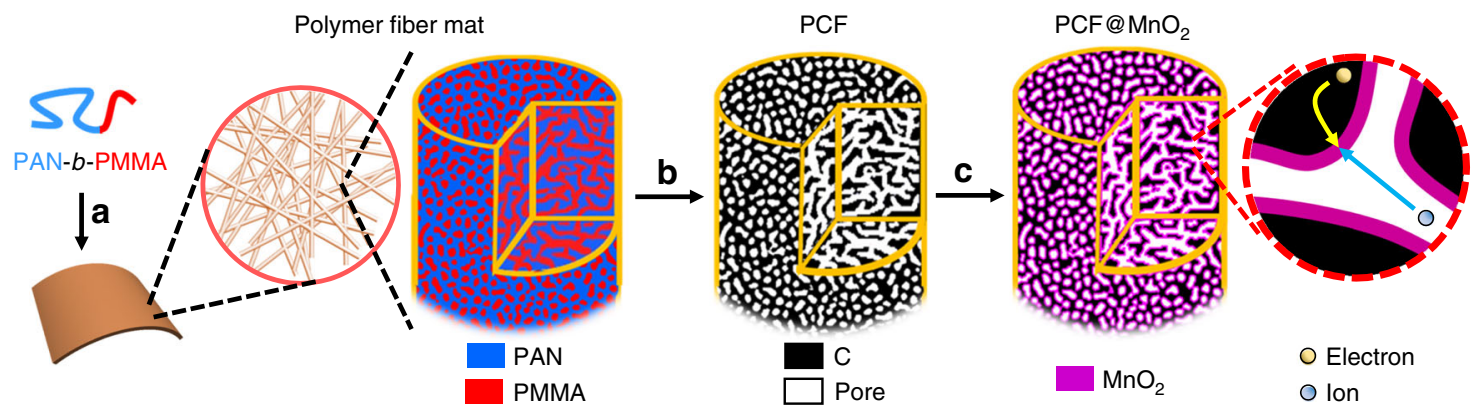

Fig. 1 Schematic illustration of the synthesis of PCF and PCF@MnO . a PAN-b-PMMA block copolymer is spun into a polymer fiber mat. (Magnified view) PAN (blue) and PMMA (red) in the block copolymer fibers microphase separate into a bicontinuous network structure. Via thermal oxidation, PAN is crosslinked to ensure a high yield of conductive carbon network. b Upon pyrolysis, the polymer fibers are converted to porous carbon fibers (PCFs, black) with continuous and uniform mesopores (white channels), which afford high loadings of transition metal oxides. c The PCFs are loaded with $\mathrm{MnO}_{2}$ (magenta) to become PCF@ $\mathrm{MnO}_{2}$ through a solution-based redox deposition reaction. (Magnified view) The continuous carbon fiber matrix and the partially filled mesoporous channels provide effective expressways for electron conduction and ion diffusion, respectively 

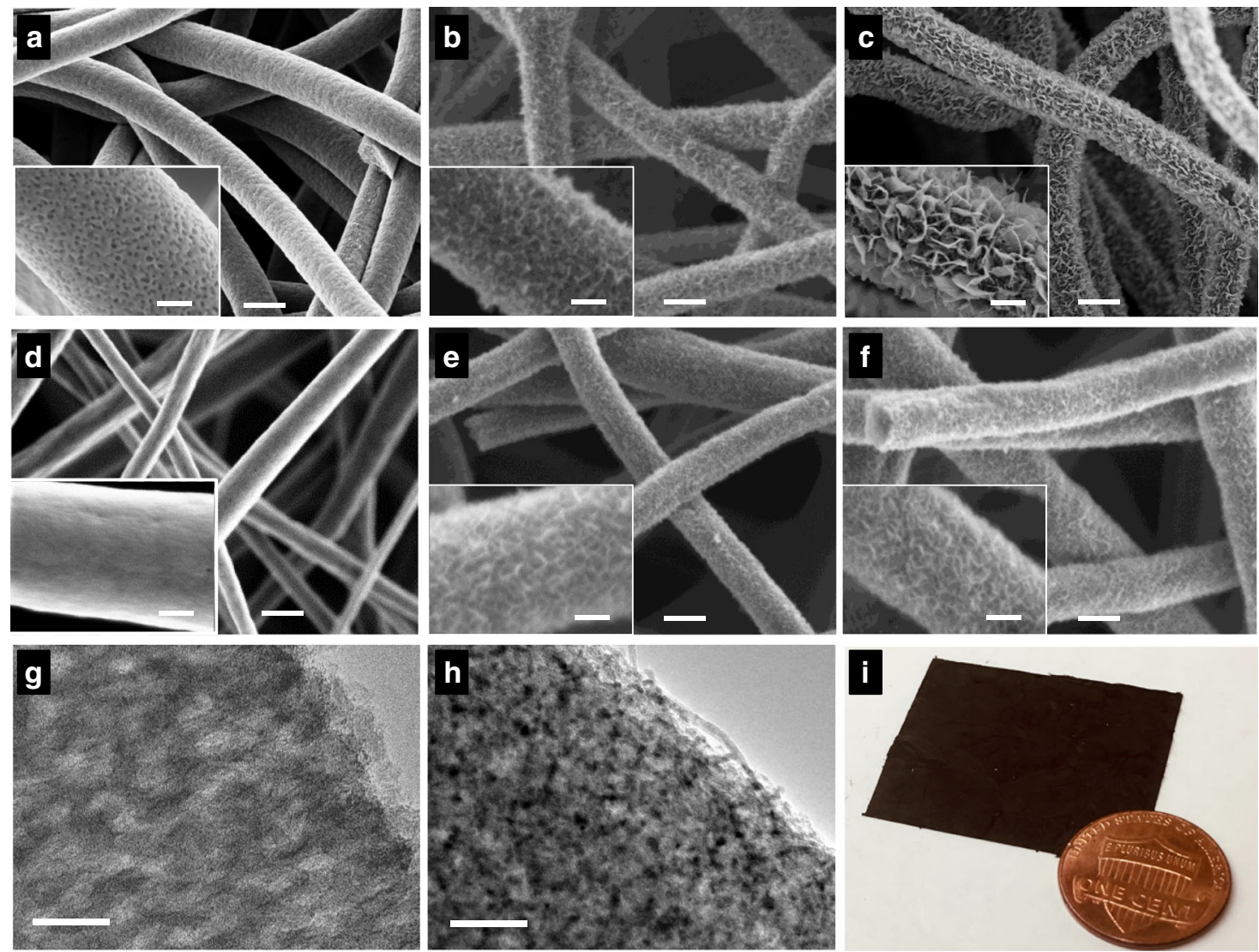

Fig. 2 Morphology characterizations. a-f SEM images of (a) PCF, (b) PCF@MnO -1 h, (c) PCF@MnO $-2 h$, (d) conventional CF, (e) CF@MnO -1 h, and (f) $\mathrm{CF} @ \mathrm{MnO}_{2}-2 \mathrm{~h}$. Scale bars: $200 \mathrm{~nm}$. (Insets) Magnified views of the single fibers. Scale bars: $50 \mathrm{~nm}$. Due to the surface effect, the interconnected mesopores in PCFs appear as discrete dark spots on the fiber skin (inset a) but are absent in the conventional CFs (inset $\mathbf{d}$ ). $\mathbf{g}, \mathbf{h}$ TEM images of PCF ( $\mathbf{g}$ ) before and (h) after loading $\mathrm{MnO}_{2}$ for $2 \mathrm{~h}$. Scale bars: $50 \mathrm{~nm}$. The $\mathrm{MnO}_{2}$ nanosheets are removed from the fiber skin to reveal the internal structures without interference. $\mathbf{g}$ The gray and dark areas correspond to the interconnected mesopores and the carbon matrix, respectively. $\mathbf{h} \mathrm{MnO}_{2}$ appear darker than carbon due to the higher atomic number. $\mathbf{i}$ A photograph of a piece of PCF@ $\mathrm{MnO}_{2}-2 \mathrm{~h}$ electrode next to a U.S. penny with a diameter of $\sim 1.9 \mathrm{~cm}$

(Figs. 2a, 3a, and Supplementary Fig. 1a) ${ }^{42}$. In contrast, the CFs derived from PAN exhibited relatively smooth surfaces and no observable mesopores under SEM (Fig. 2d and Supplementary Fig. 1b). Small angle X-ray scattering (SAXS) spectroscopy confirmed the microphase separation of PAN-b-PMMA and revealed that the average center-to-center pore-spacing in PCFs was 25.7 $\mathrm{nm}$ (Supplementary Fig. 2). The volume fraction of PAN in PAN$b$-PMMA was $\sim 65 \%$, and supposedly the block copolymer should self-assemble into either cylindrical or gyroidal structures, depending on the incompatibility of the two blocks. After pyrolysis, however, the porous carbon fibers showed no well-defined cylindrical or gyroidal structures but interconnected mesopores that were irregularly shaped and uniformly distributed, as shown in the cross-sectional SEM image (Supplementary Fig. 1a). This morphology is attributed to the crosslinking of PAN at elevated temperatures, which hindered the microphase separation of PAN-b-PMMA into well-defined cylindrical or gyroidal structures, similar to the crosslinking-induced hindering effect in previous reports ${ }^{43,44}$.

The two types of carbon fibers were immersed in aqueous solutions of potassium permanganate $\left(\mathrm{KMnO}_{4}, 10 \mathrm{mM}\right)$ at $80^{\circ} \mathrm{C}$ to deposit $\mathrm{MnO}_{2}$ on their surfaces. We chose the solution-based redox deposition because it creates a conformal and homogenous layer of $\mathrm{MnO}_{2}$ inside the pores via a self-limiting redox reaction between $\mathrm{KMnO}_{4}$ and carbon ${ }^{32,45,46}$. Compared with electrochemical deposition (Supplementary Fig. 3), the redox reaction deposition is advantageous because it yields uniform and homogeneous layers of $\mathrm{MnO}_{2}$ on PCFs that ensure a low ion diffusion resistance and thus, a high rate capability. After the deposition, the carbon fibers were washed thoroughly with deionized water, and the supernatant were analyzed with UV-vis spectroscopy to assure that there was no residual $\mathrm{KMnO}_{4}$ in the carbon fibers (Supplementary Fig. 4). As shown by SEM, $\mathrm{MnO}_{2}$ started to grow confocally on PCF within the first hour (Fig. 2b), and it continued to grow into nanosheets when the deposition time was prolonged to $2 \mathrm{~h}$ (Fig. 2c). The growth of $\mathrm{MnO}_{2}$ on conventional CFs, however, differed drastically. After depositing for $2 \mathrm{~h}$, the surface of $\mathrm{CF} @ \mathrm{MnO}_{2}-2 \mathrm{~h}$ (Fig. 2f) did not change significantly from $\mathrm{CF} @ \mathrm{MnO}_{2}-1 \mathrm{~h}$ (Fig. 2e). Only a thin layer of $\mathrm{MnO}_{2}$ nanosheets was present on the surfaces of both $\mathrm{CF} @ \mathrm{MnO}_{2}-1 \mathrm{~h}$ and $\mathrm{CF} @ \mathrm{MnO}_{2}-2 \mathrm{~h}$, confirming that the block copolymer-derived PCFs afford a much higher loading of $\mathrm{MnO}_{2}$ than pure PAN-derived CFs. To verify the successful deposition of $\mathrm{MnO}_{2}$ in the mesopores, we compared the transmission electron microscopy (TEM) images of PCF (Fig. 2g) and PCF@ $\mathrm{MnO}_{2}$-1h (Fig. 2h). Black spots of $\mathrm{MnO}_{2}$ were uniformly embedded in PCF@ $\mathrm{MnO}_{2}-1 \mathrm{~h}$, while they were absent in PCF before loading with $\mathrm{MnO}_{2}$. $\mathrm{MnO}_{2}$ appeared black because $\mathrm{Mn}$ has a higher atomic number than carbon does. The PCF mats were prepared on a large scale and ready for use as electrodes without binders or conductive additives (Fig. 2i).

Chemical and physical properties. X-ray photoelectron spectroscopy (XPS), Raman spectroscopy, and high-resolution TEM orthogonally verified the successful loading of $\mathrm{MnO}_{2}$ onto PCF. 

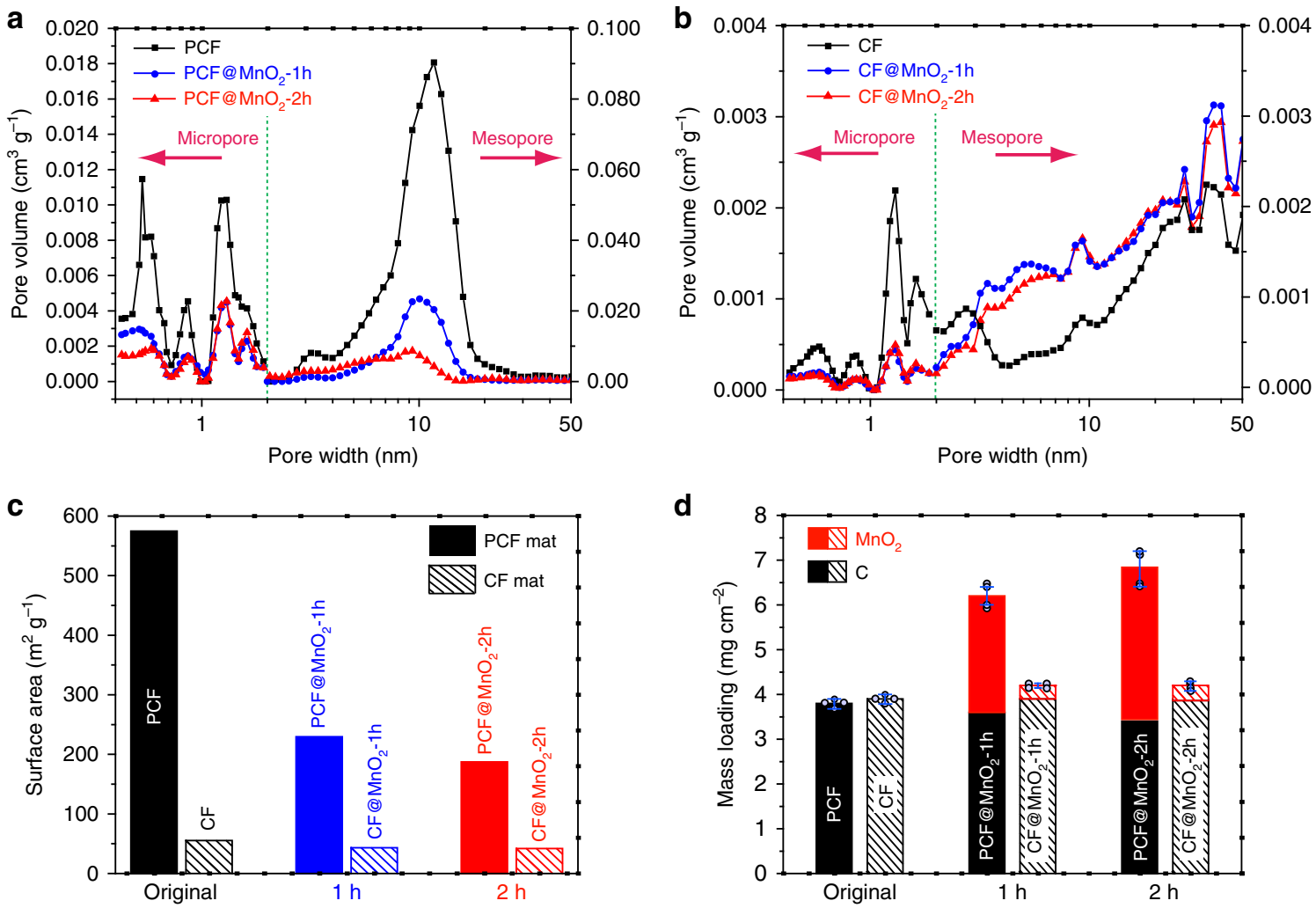

Fig. 3 Physical characterizations. a, b Pore size distributions of (a) PCF, PCF@ $\mathrm{MnO}_{2}-1 \mathrm{~h}$, and PCF@ $\mathrm{MnO}_{2}-2 \mathrm{~h}$ and (b) CF, CF@MnO $2-1 \mathrm{~h}$, and CF@MnO $-2 \mathrm{~h}$. The micropore and mesopore size distributions are measured by the physisorption of carbon dioxide (at $273 \mathrm{~K}$ ) and nitrogen (at $77 \mathrm{~K}$ ), respectively, and calculated using the density functional theory. Note the different scales in the micropore and mesopore ranges. Compared to PCFs, CFs contain one order of magnitude lower mesopore volume. The high mesopore volume of PCFs confirms that the mesopores are interconnected and thus are accessible to the adsorbates. $\mathbf{c}$ The surface areas of PCFs and CFs before and after loading $\mathrm{MnO}_{2}$. The deposition reaction time increased from 0 to $2 \mathrm{~h}$. $\mathbf{d}$ Histograms of the mass loadings of (black) carbon fibers and (red) $\mathrm{MnO}_{2}$ on supercapacitor electrodes. The solid and dashed bars represent electrodes composed of PCFs and conventional CFs, respectively. The error bars in (d) are standard deviations determined from at least four independent measurements

The XPS spectrum (Supplementary Fig. 5a) of PCF@MnO 2 -2h showed peaks of $\mathrm{C}, \mathrm{O}$, and $\mathrm{N}$ corresponding to the carbon fibers, as well as a full set of peaks corresponding to Mn. An examination of the Mn $3 s$ core-level XPS spectrum (Supplementary Fig. 5b) revealed that the separation between the doublet was $4.89 \mathrm{eV}$, corroborating the valence state of $\mathrm{Mn}(\mathrm{IV})^{47}$. After $\mathrm{MnO}_{2}$ deposition, the Raman spectrum of PCF@ $\mathrm{MnO}_{2}-2 \mathrm{~h}$ (Supplementary Fig. 6a) showed a group of peaks centered at $\sim 600 \mathrm{~cm}^{-1}$ corresponding to birnessite-phase manganese dioxide $\left(\delta-\mathrm{MnO}_{2}\right)^{48}$. The birnessite-phase of $\mathrm{MnO}_{2}$ was also proven by the characteristic lattice fringes in the lattice-resolved TEM images (Supplementary Figs. 6b, c). Among the various types of $\mathrm{MnO}_{2}, \delta-\mathrm{MnO}_{2}$ is one of the most suitable phases for fast chargedischarge because its layered structure allows for rapid ion diffusion ${ }^{49}$.

The porous structures of carbon fibers changed after loading with $\mathrm{MnO}_{2}$. The pore size distributions of mesopores and micropores were evaluated by nitrogen and carbon dioxide adsorption-desorption isotherms, respectively (Supplementary Fig. 7). PCFs possessed significantly larger numbers of both mesopores and micropores. After depositing $\mathrm{MnO}_{2}$, the micropore volumes of PCFs and CFs steadily decreased at all pore widths, but the peak positions remained unchanged (Fig. 3a, b), suggesting that the micropores were either completely filled or clogged by $\mathrm{MnO}_{2}$. The pore size distributions of PCFs and CFs, however, were different in the mesopore range. PCFs exhibited appreciable decrease in the mesopore volume after depositing $\mathrm{MnO}_{2}$. In addition, the peak position shifted from 11.7 to $10.0 \mathrm{~nm}$ after $1 \mathrm{~h}$, and further down to $9.3 \mathrm{~nm}$ after $2 \mathrm{~h}$, suggesting that the average thickness of the $\mathrm{MnO}_{2}$ layer inside the pores was $\sim 0.9 \mathrm{~nm}$ and $\sim 1.2 \mathrm{~nm}$ after depositing for 1 and $2 \mathrm{~h}$, respectively. These thicknesses are desirable for high capacitive performance, as suggested by the Au model in a previous report ${ }^{22}$. The reduction of mesopore size suggests that the mesopores were only partially filled with $\mathrm{MnO}_{2}$, and therefore they remained accessible to the gas adsorbates and ions. As shown in Supplementary Table 1, the pore volume reduced more in the mesopore range $(86.1 \%$ reduction after the 2-h deposition) than in the micropore range (66.0\% reduction after 2-h deposition). On the contrary, the mesopore volume of $\mathrm{CFs}$, which was two orders of magnitudes lower than that of PCFs, increased after depositing $\mathrm{MnO}_{2}$ (Fig. 3b). The increase in the mesopore volume of CFs is ascribed to the porous structures formed by $\mathrm{MnO}_{2}$ as shown in Fig. 2e, f. The total pore volumes of CF-based electrodes were at least one order of magnitude lower than those of PCF-based electrodes.

The incorporation of $\mathrm{MnO}_{2}$ into PCFs and CFs also altered the surface area (Fig. 3c). The surface area of the PCF mat $\left(574.8 \mathrm{~m}^{2} \mathrm{~g}^{-1}\right)$ was more than ten times higher than that of the CF mat $\left(55.31 \mathrm{~m}^{2} \mathrm{~g}^{-1}\right)$. Upon loading with $\mathrm{MnO}_{2}$, the surface area of PCFs decreased from 574.8 to $229.5 \mathrm{~m}^{2} \mathrm{~g}^{-1}$ for PCF@ $@ \mathrm{MnO}_{2}-1 \mathrm{~h}$, and further down to $187.5 \mathrm{~m}^{2} \mathrm{~g}^{-1}$ for PCF@ $\mathrm{MnO}_{2}-2 \mathrm{~h}$. In contrast, the surface area of CFs only experienced moderate decreases from 55.31 to $43.35 \mathrm{~m}^{2} \mathrm{~g}^{-1}$ for $\mathrm{CF} @ \mathrm{MnO}_{2}-1 \mathrm{~h}$ and to $41.76 \mathrm{~m}^{2} \mathrm{~g}^{-1}$ for $\mathrm{CF} @ \mathrm{MnO}_{2}-2 \mathrm{~h}$.

The higher loadings of $\mathrm{MnO}_{2}$ in PCFs than in CFs is due to the large number of uniform mesopores (Fig. 3d). The total mass loadings (including carbon fibers and $\mathrm{MnO}_{2}$ ) of PCF, PCF@MnO 2 - $1 \mathrm{~h}$, and PCF@ $\mathrm{MnO}_{2}-2 \mathrm{~h}$ were $3.8 \pm 0.1,6.2 \pm 0.3$, 

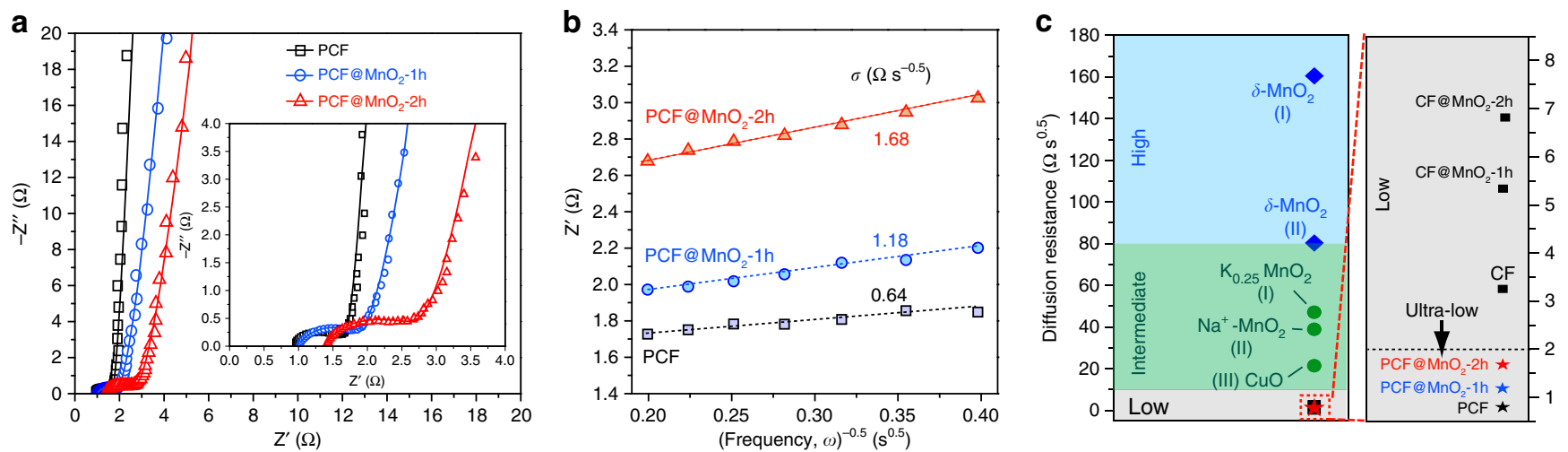

Fig. 4 Ultra-fast electron and ion transport in the PCF-based electrodes. a Nyquist plots collected at open circuit potentials with $5 \mathrm{~m} V$ perturbation and a frequency range from 10,000 to $0.1 \mathrm{~Hz}$. The open symbols are experimental data and the solid lines are fitting curves. $\mathbf{b} Z^{\prime}$ vs. the reciprocal of the square root of frequency $\left(\omega^{-0.5}\right)$ in the intermediate frequency range. The dashed lines are best fitting lines to calculate the diffusion resistance, $\sigma$. c The ion diffusion resistance of the carbon fiber electrodes in comparison with other reported electrodes: (I) Ref. 57; (II) Ref. 58; (III) Ref. 59. The CF-based electrodes show low diffusion resistance and the PCF-based electrodes show ultra-low diffusion resistance

and $6.8 \pm 0.4 \mathrm{mg} \mathrm{cm}^{-2}$, respectively. The error bars ( \pm values) are standard deviations determined from at least four independent measurements. $\mathrm{MnO}_{2}$ accounted for $42 \%$ and $50 \%$ of the total mass of PCF@ $\mathrm{MnO}_{2}-1 \mathrm{~h}$ and $\mathrm{PCF} @ \mathrm{MnO}_{2}-2 \mathrm{~h}$, respectively. In contrast, CF-based electrodes showed much smaller mass loadings of $3.9 \pm 0.1,4.2 \pm 0.1$, and $4.3 \pm 0.2 \mathrm{mg} \mathrm{cm}^{-2}$ for $\mathrm{CF}$, $\mathrm{CF} @ \mathrm{MnO}_{2}-1 \mathrm{~h}$ and $\mathrm{CF} @ \mathrm{MnO}_{2}-2 \mathrm{~h}$, respectively. $\mathrm{MnO}_{2}$ only contributed $\sim 9 \%$ of the total mass of $\mathrm{CF@MnO}-1 \mathrm{~h}$ and $\mathrm{CF} @ \mathrm{MnO}_{2}-2 \mathrm{~h}$. The difference in the mass loading of $\mathrm{MnO}_{2}$ on PCFs and CFs is also apparent in the SEM images (Fig. 2). The comparison shows that the uniform mesopores are indispensable in realizing the high mass loading of $\mathrm{MnO}_{2}$ on the carbon fibers. The abundant mesopores provide large solution-accessible surface areas for loading $\mathrm{MnO}_{2}$ on the PCFs, while micropores can only host a limited amount of $\mathrm{MnO}_{2}$ because the deposition solution can barely access them. The mass of all carbon fibers reduced slightly after loading with $\mathrm{MnO}_{2}$, due to the consumption of carbon by the redox reaction between carbon and $\mathrm{KMnO}_{4}$. Further elongating the deposition time to $3 \mathrm{~h}$ showed no appreciable increase in $\mathrm{MnO}_{2}$ loading, confirming that the redox deposition was self-limited.

Ultra-fast electron and ion transport. Considering the high loading of $\mathrm{MnO}_{2}$ and the large number of mesopores for ion transport, we investigated the performance of the PCF-based electrodes for pseudocapacitors. The electron transport and ion diffusion resistivity were analyzed with electrochemical impedance spectroscopy (EIS). The Nyquist plots of PCF, PCF@MnO${ }_{2}-1$ h and PCF@ $\mathrm{MnO}_{2}-2 \mathrm{~h}$ (Fig. 4a) exhibited incomplete semicircles followed by linear tails, which resemble the features of mixed kinetic-diffusion-controlled processes and are typical for pseudocapacitive materials ${ }^{50}$. To obtain the resistances, we fitted the EIS spectra with an equivalent electric circuit (Supplementary Fig. 8). The combined series resistances $\left(R_{\mathrm{s}}\right)$ of PCF and PCF@ $\mathrm{MnO}_{2}-1 \mathrm{~h}$ were $1.0 \Omega$, and that of PCF@MnO $\mathrm{Mn}_{2}-2 \mathrm{~h}$ increased to $1.4 \Omega$ (Fig. $4 \mathrm{a}$ inset). The $R_{\mathrm{s}}$ values were comparable to highly conductive carbon-based materials in aqueous electrolytes ${ }^{51-53}$, indicating that $\mathrm{MnO}_{2}$ introduced minimal changes to the electrical resistance of the electrodes despite the high loadings. In addition, the charge-transfer resistances $\left(R_{\mathrm{ct}}\right.$, the semicircles in Fig. 4a inset) of PCF, PCF@ $\mathrm{MnO}_{2}-1 \mathrm{~h}$ and PCF@ $\mathrm{MnO}_{2}-2 \mathrm{~h}$ are $0.74,0.86$ and $1.30 \Omega$, respectively. The small resistances suggest efficient electron transfer associated with the redox reaction of $\mathrm{MnO}_{2}$. The augmentation of charge-transfer resistance in $\mathrm{PCF} @ \mathrm{MnO}_{2}-2 \mathrm{~h}$ is mainly due to the increased thickness of $\mathrm{MnO}_{2}$ deposited in the mesopores (evidenced by the reduction in mesopore-width shown in Fig. 3d). The increased thickness elongates the electron transport distance in $\mathrm{MnO}_{2}$ and therefore obstructs electron transfer at the $\mathrm{MnO}_{2}$ /electrolyte interface, because $\mathrm{MnO}_{2}$ is a poor electron conductor $\left(10^{-5} \sim 10^{-6} \mathrm{~S} \mathrm{~cm}^{-1}\right)$. The small $R_{\mathrm{s}}$ and $R_{\mathrm{ct}}$ are key attributes of the block copolymer-based carbon fiber electrodes because 1) unlike discrete carbon particles or graphene flakes, the carbon fibers offer continuous expressways for electron conduction, and 2) the block copolymers endow the carbon fibers with high surface areas to load with an ultrathin layer of $\delta-\mathrm{MnO}_{2}$, which mitigates the insulating problem and facilitates the electron transport.

In addition to the efficient electron transport, the block copolymer-derived PCF electrodes exhibited ultra-fast ion diffusion kinetics, as featured by their ultra-small diffusion resistances $(\sigma)$. The values of $\sigma$ were extracted from the slopes of the linear fitting lines of the real part of impedance $\left(Z^{\prime}\right)$ versus the reciprocal of the square root of frequency $\left(\omega^{-0.5}\right)$ (Fig. $4 \mathrm{~b}$ ). PCFs displayed the smallest $\sigma$ of $0.64 \Omega \mathrm{s}^{-0.5}$, followed by PCF@ $\mathrm{MnO}_{2}-1 \mathrm{~h}(1.18$ $\left.\Omega \mathrm{s}^{-0.5}\right)$ and PCF@ $\mathrm{MnO}_{2}-2 \mathrm{~h}\left(1.68 \Omega \mathrm{s}^{-0.5}\right)$. The slight increase in $\sigma$ is in accordance with the fact that the pseudocapacitive reactions are slower than the adsorption-desorption of ions pertaining to the electrical double layer capacitive processes, as well as that the mesopore size is reduced. Despite the increase, the $\sigma$ values of our PCF-based electrodes were remarkably smaller than other $\mathrm{MnO}_{2}$-based materials (Fig. 4c). Notably, the $\sigma$ value of PCF@MnO $\mathrm{Mn}_{2}-2 \mathrm{~h}$ was even lower than that of CF (Fig. $4 \mathrm{c}$ and Supplementary Fig. 9), a mostly electrical double layer capacitive (EDLC) material that has fast ion diffusion kinetics. In addition, the $\sigma$ value of PCF@ $\mathrm{MnO}_{2}-2 \mathrm{~h}\left(<2 \Omega \mathrm{s}^{-0.5}\right)$ is $\sim 3.5$ times lower than that of $\mathrm{CF} @ \mathrm{MnO}_{2}-2 \mathrm{~h}\left(\sim 7 \Omega \mathrm{s}^{-0.5}\right)$, highlighting the critical role of the uniform distributed, randomly oriented, and interconnected mesopores in accelerating electrolyte infiltration and ion diffusion in block copolymer-derived PCFs.

Pseudocapacitive performance. With continuous electron conduction and ultra-low ion diffusion resistivity, $\mathrm{PCF} @ \mathrm{MnO}_{2}-2 \mathrm{~h}$ exhibited ultra-fast charge and discharge kinetics. The cyclic voltammograms (CVs) of $\mathrm{PCF} @ \mathrm{MnO}_{2}-2 \mathrm{~h}$ were nearly rectangular (Fig. 5a), reflecting the rapid electron and ion transport in the electrode ${ }^{54}$. The current density of a supercapacitor, $i$, scales with the scan rate, $v$, following the relationship of $i=\mathrm{k} v^{\mathrm{b}}$. The power-law exponent, $b$, is an important metric to evaluate the charge-storage kinetics, and $b=1$ for an ideal supercapacitor. By 

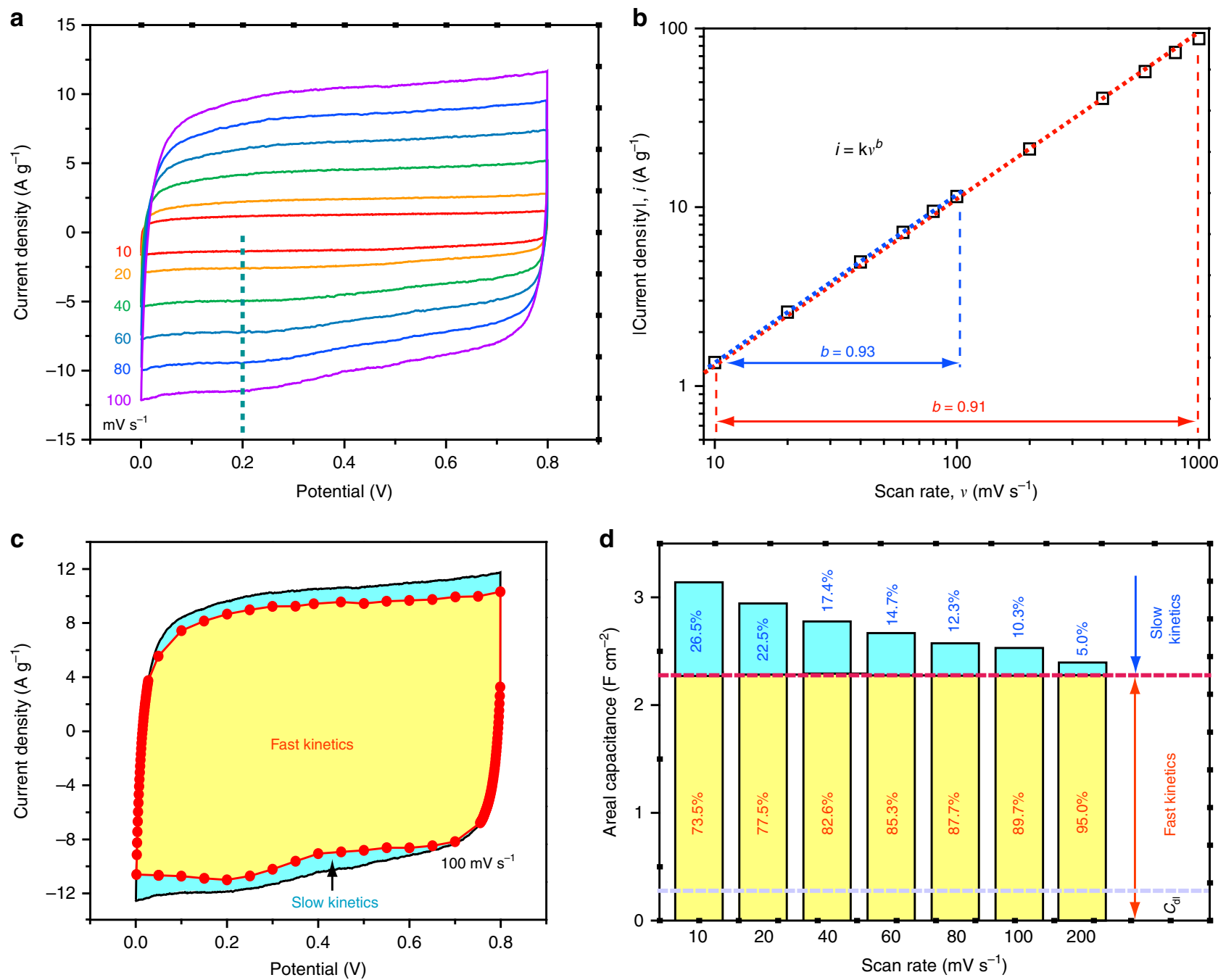

Fig. 5 Ultra-fast charge-storage kinetics of PCF@ $\mathrm{MnO}_{2}-2 \mathrm{~h}$. a CVs at various scan rates from 10 to $100 \mathrm{mV} \mathrm{s}^{-1}$. The dashed line highlights the potential $(0.2 \mathrm{~V})$ selected for the $b$ value calculation. $\mathbf{b}$ Absolute current density and scan rate follow the power law, $i=\mathrm{kv}^{b}$, in both the slow and fast scan rate regions. The dashed lines are best fitting lines and the $b$-value changes only slightly from the slow scan region to the fast scan region. $\mathbf{c}$ Decoupling of the capacitance contributed by the fast-kinetic processes (yellow) and the slow-kinetic processes (blue). Even at a high mass loading of $\mathrm{MnO}_{2}(50 \%$ of the total mass), the fast-kinetics capacitance still dominates the overall capacitance. $\mathbf{d}$ Histograms of the capacitance contributions by the different processes: Yellow, fast-kinetic processes; blue, slow-kinetic processes; $C_{d d}$, electrical double layer capacitance

plotting the logarithm of the absolute cathodic current densities at $0.2 \mathrm{~V}$ against the logarithm of scan rates (Fig. $5 \mathrm{~b}$ ), the $b$-value was calculated to be 0.93 in the scan-rate range of $10-100 \mathrm{mV} \mathrm{s}^{-1}$, approaching that of an ideal capacitor $(b=1)$ and suggesting the ultra-fast charge-storage kinetics. Outstandingly, the $b$ value decreases only slightly to 0.91 in the range of $10-1000 \mathrm{mV} \mathrm{s}^{-1}$, unambiguously confirming its fast charge-storage kinetics.

We further decoupled the capacitances from fast-kinetic processes and slow-kinetic processes. The decoupling is based on the different contributions of fast and slow kinetics processes in the current density of a CV curve (see Supplementary Methods for details). Briefly, the current density at a fixed potential and a scan rate, $i$ is composed of two terms associated with the scan rate, $v$ :

$$
i=\mathrm{k}_{1} v+\mathrm{k}_{2} v^{0.5}
$$

where $\mathrm{k}_{1}$ and $\mathrm{k}_{2}$ are constants. The first term $\mathrm{k}_{1} v$ equals the current density contributed from fast-kinetic processes and the second term $\mathrm{k}_{2} v^{0.5}$ is the current density associated with slow- kinetic (or diffusion-controlled) processes. Dividing $v^{0.5}$ on both sides of Equation (1) gives:

$$
i v^{-0.5}=\mathrm{k}_{1} v^{0.5}+\mathrm{k}_{2} .
$$

Equation (2) shows that $i v^{0.5}$ and $v^{0.5}$ are expected to have a linear relationship, with $k_{1}$ and $k_{2}$ being the slope and the $\mathrm{y}$ intercept, respectively. Repeating the above step at other scan rates reveals the current density contribution across the potential window and outlines the contribution from the fast-kinetic and slow-kinetic processes. Figure $5 c$ shows an example of the decoupling of a $\mathrm{CV}$ at $100 \mathrm{mV} \mathrm{s}^{-1}$. The capacitive contribution from the fast-kinetic processes (yellow region) clearly dominates that of the slow-kinetic processes (blue region) at all scan rates (Fig. 5c-d, Supplementary Fig. 10). The slow-kinetic capacitance decreased with the increasing scan rate. Importantly, the electric double layer capacitance $\left(\mathrm{C}_{\mathrm{dl}}\right)$ contributed only a small fraction in the fast-kinetics region (Fig. $5 \mathrm{~d}$, gray dashed line), indicating that the majority of the pseudocapacitance of $\mathrm{PCF} @ \mathrm{MnO}_{2}-2 \mathrm{~h}$ is not 

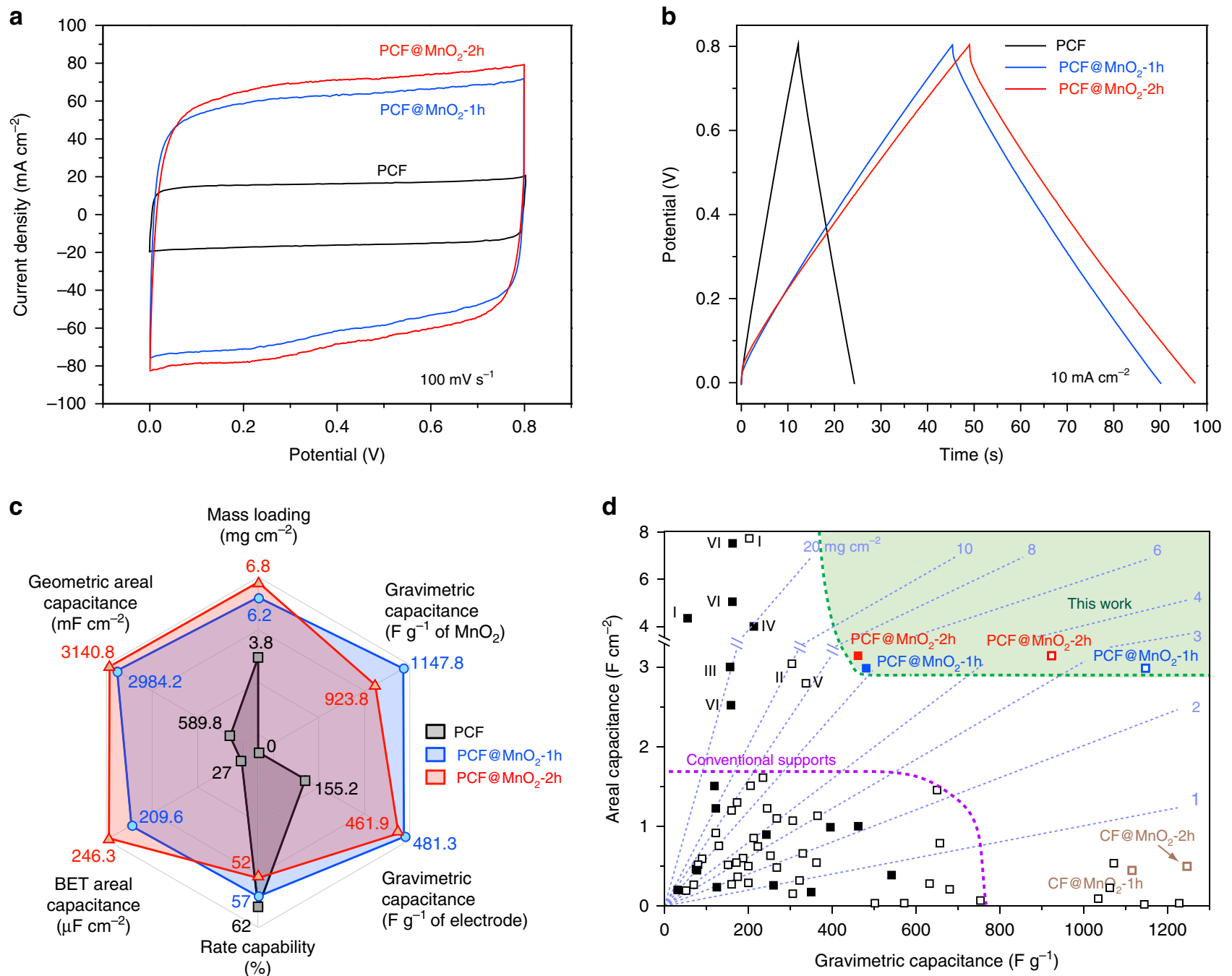

Fig. 6 Electrochemical performance of PCF, PCF@MnO $2-1$ h and PCF@ $\mathrm{MnO}_{2}-2 \mathrm{~h}$. a CVs at a scan rate of $100 \mathrm{mV} \mathrm{s}^{-1}$. b Galvanostatic charge-discharge curves at 10 mA cm ${ }^{-2}$ of PCF (black), PCF@ $\mathrm{MnO}_{2}-1 \mathrm{~h}$ (blue), and PCF@ $\mathrm{MnO}_{2}-2 \mathrm{~h}$ (red). c The radar chart compares the six figure-of-merits of PCF (black), PCF@MnO -1 h (blue), and PCF@ $\mathrm{MnO}_{2}-2 \mathrm{~h}$ (red): mass loading of the active materials, rate capability (from 10 to $1000 \mathrm{mV} \mathrm{s}^{-1}$ ), gravimetric capacitance based on the mass of $\mathrm{MnO}_{2}$ and the active materials, and areal capacitance based on the geometric area and BET surface area. All capacitances are obtained at $10 \mathrm{mV} \mathrm{s}^{-1}$. d Mass loading, gravimetric capacitance, and geometric areal capacitance of PCF-based electrodes in comparison with other reported electrodes. Dashed lines mark the mass loadings in $\mathrm{mg} \mathrm{cm}^{-2}$. Open and filled squares are capacitances based on the mass loadings of $\mathrm{MnO}_{2}$ and the entire electrodes, respectively. Note that the open (and filled) squares are only to be compared with open (and filled) squares. The labeled points: I, wood-derived porous carbon@ $\mathrm{MnO}_{2} i^{14} \mathrm{II}$, hierarchical $\mathrm{MnO}_{2}$ on carbon cloth; ${ }^{12} \mathrm{III}$, carbon nanotube (CNT)@MnO ${ }_{2} ; 0 \mathrm{IV}$, activated carbon-coated $\mathrm{CNT} @ \mathrm{MnO}_{2} \cdot{ }^{61} \mathrm{~V}, \mathrm{CNT}$-wrapped polyester fiber@ $\mathrm{MnO}_{2},{ }^{16} \mathrm{VI}$, carbon nanofoam@ $\mathrm{MnO}_{2}{ }^{33}$. The details of all the unlabeled data points are summarized in Supplementary Table 2

charge-transfer-limited or diffusion-controlled. The fast kinetics makes PCF@ $\mathrm{MnO}_{2}$ a desirable pseudocapacitive electrode for rapid charge storage and release.

We measured the electrochemical capacitive performance of our carbon fiber electrodes. Among the PCF-based electrodes, PCF@ $\mathrm{MnO}_{2}-2 \mathrm{~h}$ displayed the highest areal capacitance, as shown by the CVs (Fig. 6a) and the galvanostatic charge-discharge (GCD) profiles (Fig. 6b). The negligible deviation of the CVs from the rectangular shape and the isosceles triangular GCD profiles at high $10 \mathrm{~mA} \mathrm{~cm}^{-2}$ echoed the fast charge-storage kinetics of PCF@ $\mathrm{MnO}_{2}$. A radar chart (Fig. 6c) summarizes the six figure-ofmerits of a pseudocapacitor electrode, i.e., mass loading, gravimetric capacitance normalized to the mass of $\mathrm{MnO}_{2}$, gravimetric capacitance normalized to the mass of electrode, areal capacitance normalized to geometric surface area, areal capacitance normalized to BET surface area, and rate capability. Due to the lower mass loading of PCF@MnO $\mathrm{Mn}_{2}-1 \mathrm{~h}$ than that of
$\mathrm{PCF} @ \mathrm{MnO}_{2}-2 \mathrm{~h}$, the former achieved higher values in gravimetric capacitance and rate capability. Remarkably, the gravimetric capacitance of PCF@ $\mathrm{MnO}_{2}-1 \mathrm{~h}$ at $10 \mathrm{mV} \mathrm{s}^{-1}$ reached $1148 \mathrm{~F} \mathrm{~g}^{-1}$ of $\mathrm{MnO}_{2}$. This value is $~ 84 \%$ of the theoretical gravimetric capacitance of $\mathrm{MnO}_{2}\left(1367 \mathrm{~F} \mathrm{~g}^{-1}\right)$ within a potential window of $0.8 \mathrm{~V}$, even slightly higher than those on the model supports of mesoporous $\mathrm{Au}^{22,23}$ and dendritic $\mathrm{Ni}^{26}$, suggesting almost all the $\mathrm{MnO}_{2}$ loaded on PCFs was accessible to the ions and contributed to the high capacitance. PCF@MnO${ }_{2}$-2h displayed the highest areal capacitance owing to its highest mass loading. PCF exhibited the best rate capability because it charges/discharges mostly via electrical double layers. Full comparison of the gravimetric, areal, and volumetric capacitances of PCF-based and CF-based electrodes at various scan rates are summarized in Supplementary Figs 11 and 12. Markedly, the gravimetric capacitance and geometric areal capacitance of PCF@MnO $2-2 h$ outperformed the previously-reported $\mathrm{MnO}_{2}$ electrodes at 
comparable mass loadings under similar testing conditions (Fig. 6d and Supplementary Table 2). Ideally, with fast electron and ion transport at high mass loadings, both the areal and gravimetric capacitances are expected to be high. However, most reported $\mathrm{MnO}_{2}$ electrodes have poor areal and/or gravimetric capacitances. In contrast, our PCF-supported $\mathrm{MnO}_{2}$ electrodes have both high areal and gravimetric capacitances. PCF@ $\mathrm{MnO}_{2}-$ $2 \mathrm{~h}$ was also highly stable, retaining more than $98 \%$ of the initial capacitance after 5000 consecutive charge-discharge cycles (Supplementary Fig. 13).

The Ragone plot (Supplementary Fig. 14) compares the specific energy and power densities of PCF@ $\mathrm{MnO}_{2}$ with those of the $\mathrm{MnO}_{2}$ supported on graphene, a star material for supercapacitor electrodes. With a high gravimetric power density of $23.2 \mathrm{~kW} \mathrm{~kg}$ -1 and a high gravimetric energy density of $10.3 \mathrm{Wh} \mathrm{kg}^{-1}$ in the tested range of scan rates, $\mathrm{PCF} @ \mathrm{MnO}_{2}-2 \mathrm{~h}$ outperformed the various graphene- and CF-supported $\mathrm{MnO}_{2}$ electrodes in symmetric pseudocapacitors. The superior capacitive performance signifies that our PCF-supported $\mathrm{MnO}_{2}$ electrodes have realized both high mass loadings and ultrafast charge transport kinetics.

\section{Discussion}

The judiciously designed comparison between our PCFs and conventional CFs proves that PCFs with uniform mesopores are superior carbon supports for addressing the two long-lasting challenges of pseudocapacitors: high mass loading and fast charge transport. Utilizing the concept of block copolymer self-assembly and microphase separation, PCFs provide abundant mesopores with a large surface area for high mass loadings of ultrathin $(<2$ $\mathrm{nm})$ pseudocapactive materials. On the one hand, the ultrathin pseudocapactive material, along with the continuous fibrous carbon network, renders the composite electrode fast electron transport. On the other hand, the partially filled mesopores provide continuous and wide-open channels for effective ion transport with little diffusion resistance, even at high mass loadings approaching $7 \mathrm{mg} \mathrm{cm}^{-2}$. The $\mathrm{PCF} @ \mathrm{MnO}_{2}$ electrodes show outstanding and balanced gravimetric capacitance, areal capacitance, and rate capability, which outperform other $\mathrm{MnO}_{2}$ based pseudocapacitive electrodes at comparable mass loadings and testing conditions. Future investigations on the interplays among the polymer molecular weight, mesopore size, mass loading of $\mathrm{MnO}_{2}$, ion diffusion resistivity and the use of ionic liquid electrolytes ${ }^{55}$ are expected to further optimize the capacitive performance of PCF@ $\mathrm{MnO}_{2}$ and enhance the energy density of the supercapacitors.

This work signifies the great potential of leveraging the disparate and innovative concept of block copolymer microphase separation to design and fabricate mesoporous carbon fiber supports. We emphasize that the highly uniform mesopores are crucial for the high loading of guest materials and the efficient transport of ions. The block copolymer-derived PCFs revolutionize the porous carbon supports and are adaptable to a broad range of electrochemical applications including batteries, fuel cells, catalyst supports, and capacitive desalination devices.

\footnotetext{
Methods

Synthesis of porous carbon fiber mats. Porous carbon fiber (PCF) mats were derived from poly(acrylonitrile-block-methylmethacrylate) (PAN-b-PMMA) block copolymer. Briefly, PAN- $b$-PMMA $\left(M_{\mathrm{n}}=110-b-60 \mathrm{kDa}\right.$, polydispersity $\left.=1.14\right)$ was synthesized via reversible addition-fragmentation chain-transfer polymerization $^{56}$ and electrospun into a polymer fiber mat. The polymer fiber mat was cut into small stripes (e.g., $10 \mathrm{~cm} \times 2 \mathrm{~cm}$ ), loaded into a tube furnace (Thermo-Fisher Scientific, Model STF55433C-1), and then heated at $280^{\circ} \mathrm{C}$ for $8 \mathrm{~h}$ (ramp rate: $1^{\circ} \mathrm{C} \mathrm{min}^{-1}$ ) in air. The heating process induced the microphase separation of PAN and PMMA, and it triggered the crosslinking and cyclization of PAN. The resulting brown mats were further heated at $1200{ }^{\circ} \mathrm{C}$ for $1 \mathrm{~h}\left(\right.$ ramp rate: $\left.10^{\circ} \mathrm{C} \mathrm{min}-1\right)$ under
}

a nitrogen atmosphere. Afterwards, the tube furnace was cooled down to room temperature and PCF mats were obtained. The preparation of CF was similar except that PAN was used instead of PAN- $b$-PMMA.

Deposition of Manganese Dioxide. Manganese dioxide $\left(\mathrm{MnO}_{2}\right)$ was deposited onto the PCF mats via a solution-based self-limiting redox reaction with potassium permanganate $\left(\mathrm{KMnO}_{4}\right)$,

$$
4 \mathrm{KMnO}_{4}+3 \mathrm{C}+\mathrm{H}_{2} \mathrm{O} \rightarrow 4 \mathrm{MnO}_{2}+\mathrm{K}_{2} \mathrm{CO}_{3}+2 \mathrm{KHCO}_{3}
$$

First, $0.032 \mathrm{~g}$ of $\mathrm{KMnO}_{4}$ powder was dissolved in $20 \mathrm{~mL}$ of deionized water and used as the deposition solution $\left(\mathrm{KMnO}_{4}, 10 \mathrm{mM}\right)$. The solution was then heated to $80^{\circ} \mathrm{C}$ under ambient pressure. Approximately $10 \mathrm{mg}$ of PCF mats were soaked in the solution for $1-2 \mathrm{~h}$ under gentle stirring. After the reaction, the $\mathrm{KMnO}_{4}$ solution was drained and the remaining carbon fiber mats were thoroughly washed with deionized water five times, followed by drying in a vacuum oven at $60{ }^{\circ} \mathrm{C}$ for $8 \mathrm{~h}$. The resulting carbon fiber mats are designated as $\mathrm{PCF} @ \mathrm{MnO}_{2}-1 \mathrm{~h}$ and $\mathrm{PCF} @ \mathrm{MnO}_{2}-2 \mathrm{~h}$ based on the reaction times of $1 \mathrm{~h}$ and $2 \mathrm{~h}$, respectively.

The mass loading of $\mathrm{MnO}_{2}$ was determined by calculating the mass difference between the PCF mats before and after the reaction (see Supporting Information for detailed calculations). The areal mass loadings of $\mathrm{MnO}_{2}$ in $\mathrm{PCF} @ \mathrm{MnO}_{2}-1 \mathrm{~h}$ and PCF@ $\mathrm{MnO}_{2}$ - $\mathrm{h}$ were $2.6 \pm 0.2$ and $3.4 \pm 0.4 \mathrm{mg} \mathrm{cm}^{-2}$, respectively. The total mass loadings (including PCF and $\mathrm{MnO}_{2}$ ) of PCF@MnO $2-1 \mathrm{~h}$ and $\mathrm{PCF} @ \mathrm{MnO}_{2}-2 \mathrm{~h}$ were $6.2 \pm 0.3$ and $6.8 \pm 0.4 \mathrm{mg} \mathrm{cm}^{-2}$, respectively. The average thickness of all PCF, PCF@MnO $2-1 \mathrm{~h}$ and PCF@ $\mathrm{MnO}_{2}-2 \mathrm{~h}$ mats was $\sim 200 \mu \mathrm{m}$. Thus, the volumetric mass densities of PCF@ $\mathrm{MnO}_{2}-1 \mathrm{~h}$ and PCF@ $\mathrm{MnO}_{2}-2 \mathrm{~h}$ were $0.31 \pm 0.02$ and $0.34 \pm$ $0.02 \mathrm{~g} \mathrm{~cm}^{-3}$, respectively. The standard deviations were based on at least three batches of carbon fiber based electrodes.

Electrochemical deposition was also adopted to prepare $\mathrm{PCF} @ \mathrm{MnO}_{2}$ electrodes with high mass loadings. The electrodeposition solution contained $0.1 \mathrm{M}$ manganese acetate and $0.5 \mathrm{M}$ lithium chloride (a supporting electrolyte) in deionized water. A piece of PCF carbon fiber mat, a piece of nickel foam, and an $\mathrm{Ag} / \mathrm{AgCl}$ wire in saturated $\mathrm{KCl}$ aqueous solution were used as the working electrode, the counter electrode, and the reference electrode, respectively. The electrodes were connected to an electrochemical workstation (PARSTATS 4000+, Princeton Applied Research, Ametek Inc.) and scanned between 0 and $1.0 \mathrm{~V} v \mathrm{~s} . \mathrm{Ag} /$ $\mathrm{AgCl}$ at a scan rate of $0.01 \mathrm{mV} \mathrm{s}^{-1}$ for 15 cycles. The mass loading of the electrodeposited $\mathrm{MnO}_{2}$ on the PCF was $4.2 \mathrm{mg} \mathrm{cm}^{-2}$. The total mass loading (including $\mathrm{PCF}$ and $\mathrm{MnO}_{2}$ ) from electrodeposition was $\sim 8.0 \mathrm{mg} \mathrm{cm}^{-2}$.

Physical Characterizations. The carbon fibers were characterized using scanning electron microscopy (SEM, LEO Zeiss 1550, acceleration voltage: $2 \mathrm{kV}$ ) and highresolution transmission electron microscopy (HRTEM, FEI TITAN 300, acceleration voltage: $300 \mathrm{kV}$ ). The physisorption isotherms were measured with a pore analyzer (3Flex Pore Analyzer, Micromeritics Instrument Corp.) using nitrogen (for mesopores) and carbon dioxide (for micropores). Prior to the sorption tests, all electrodes were heated at $90^{\circ} \mathrm{C}$ for $60 \mathrm{~min}$ and then at $200^{\circ} \mathrm{C}$ for $900 \mathrm{~min}$ in $\mathrm{N}_{2}$ to desorb any moisture and hydrocarbons. The ramping rate of both heating processes was $10^{\circ} \mathrm{C} \mathrm{min}-1$. The surface areas were calculated using the BrunauerEmmett-Teller (BET) method, and the pore size distributions were obtained by the density functional theory. X-ray photoelectron spectroscopy (XPS) spectra were acquired using monochromatic Al $K_{\alpha} \mathrm{X}$-ray source $(1486.6 \mathrm{eV})$ with a $200 \mu \mathrm{m} \mathrm{X}$ ray beam at an incident angle of $45^{\circ}$. All binding energies were referenced to adventitious $\mathrm{C} 1 \mathrm{~s}$ at $284.8 \mathrm{eV}$. Chemical states of elements were assigned based on the National Institute of Standards and Technology (NIST) XPS Database. Raman spectra were recorded by a Raman spectrometer (WITec alpha 500) coupled with a confocal Raman microscope using a laser excitation wavelength of $633 \mathrm{~nm}$. UV-vis spectra were measured by an Agilent Cary $60 \mathrm{UV}$-vis spectrometer. Small angle Xray scattering (SAXS) spectra were collected by a Bruker N8 Horizon instrument with $\mathrm{Cu} K_{\alpha}$ radiation $(\lambda=1.54 \AA)$ at a current of $1 \mathrm{~mA}$ and a generator voltage of $50 \mathrm{kV}$.

Electrochemical characterizations. The electrochemical performance was evaluated in a symmetric two-electrode configuration in an aqueous electrolyte of $6 \mathrm{M}$ $\mathrm{KOH}$. For consistency, carbon fiber mats were sandwiched between two pieces of nickel foams (EQ-bcnf- $80 \mu \mathrm{m}$, MTI corporation). Cyclic voltammograms were collected within a potential window of $0-0.8 \mathrm{~V}$ at various scan rates of $10-1000$ $\mathrm{mV} \mathrm{s}^{-1}$. Galvanostatic charge and discharge (GCD) were performed within the same potential window $(0-0.8 \mathrm{~V})$. Electrochemical impedance spectroscopy was conducted at open circuit potentials with frequencies between $0.1 \mathrm{~Hz}$ and $100 \mathrm{kHz}$ with a perturbation of $5 \mathrm{mV}$. The CVs and EIS were recorded using a PARSTATS $4000+$ electrochemical workstation (Princeton Applied Research, Ametek Inc.). The GCD curves were acquired from a charge-discharge cycler (Model 580, Scribner Associates Inc.) 


\section{Data Availability}

Data supporting the findings of this study are available in this paper and in the Supplementary Information or are available from the corresponding author upon reasonable request.

Received: 31 August 2018 Accepted: 18 January 2019

Published online: 08 February 2019

\section{References}

1. Salanne, M. et al. Efficient storage mechanisms for building better supercapacitors. Nat. Energy 1, 16070 (2016).

2. Pech, D. et al. Ultrahigh-power micrometre-sized supercapacitors based on onion-like carbon. Nat. Nanotechnol. 5, 651-654 (2010).

3. Simon, P. \& Gogotsi, Y. Materials for electrochemical capacitors. Nat. Mater. 7, 845-854 (2008).

4. Miller, J. R. \& Simon, P. Electrochemical capacitors for energy management. Science 321, 651-652 (2008).

5. Wang, J.-G., Kang, F. \& Wei, B. Engineering of $\mathrm{MnO}_{2}$-based nanocomposites for high-performance supercapacitors. Prog. Mater. Sci. 74, 51-124 (2015).

6. $\mathrm{Hu}, \mathrm{Z}$. et al. Al-doped $\alpha-\mathrm{MnO}_{2}$ for high mass-loading pseudocapacitor with excellent cycling stability. Nano Energy 11, 226-234 (2015).

7. Bélanger, D., Brousse, T. \& Long, J. W. Manganese oxides: battery materials make the leap to electrochemical capacitors. Interface 17, 49-52 (2008).

8. Lee, H. Y. \& Goodenough, J. B. Supercapacitor behavior with $\mathrm{KCl}$ electrolyte. J. Solid State Chem. 144, 220-223 (1999).

9. Toupin, M., Brousse, T. \& Bélanger, D. Charge storage mechanism of $\mathrm{MnO}_{2}$ electrode used in aqueous electrochemical capacitor. Chem. Mater. 16, 3184-3190 (2004).

10. Balducci, A., Belanger, D., Brousse, T., Long, J. W. \& Sugimoto, W. A guideline for reporting performance metrics with electrochemical capacitors: from electrode materials to full devices. J. Electrochem. Soc. 164, A1487-A1488 (2017).

11. Song, Y. et al. Ostwald ripening improves rate capability of high mass loading manganese oxide for supercapacitors. ACS Energy Lett. 2, 1752-1759 (2017).

12. Huang, Z. H. et al. High mass loading $\mathrm{MnO}_{2}$ with hierarchical nanostructures for supercapacitors. ACS Nano 12, 3557-3567 (2018)

13. Wang, L. et al. Three-dimensional kenaf stem-derived porous carbon $/ \mathrm{MnO}_{2}$ for high-performance supercapacitors. Electrochim. Acta 135, 380-387 (2014).

14. Chen, C. et al. All-wood, low tortuosity, aqueous, biodegradable supercapacitors with ultra-high capacitance. Energy Environ. Sci. 10, 538-545 (2017).

15. Huang, M., Li, F., Dong, F., Zhang, Y. X. \& Zhang, L. L. $\mathrm{MnO}_{2}$-based nanostructures for high-performance supercapacitors. J. Mater. Chem. A 3, 21380-21423 (2015).

16. $\mathrm{Hu}, \mathrm{L}$. et al. Symmetrical $\mathrm{MnO}_{2}$-carbon nanotube-textile nanostructures for wearable pseudocapacitors with high mass Loading. ACS Nano 5, 8904-8913 (2011).

17. Hou, Y., Cheng, Y., Hobson, T. \& Liu, J. Design and synthesis of hierarchical $\mathrm{MnO}_{2}$ nanospheres/carbon nanotubes/conducting polymer ternary composite for high performance electrochemical electrodes. Nano Lett. 10, 2727-2733 (2010).

18. Narubayashi, M., Chen, Z., Hasegawa, K. \& Noda, S. 50-100 $\mu$ m-thick pseudocapacitive electrodes of $\mathrm{MnO}_{2}$ nanoparticles uniformly electrodeposited in carbon nanotube papers. RSC Adv. 6, 41496-41505 (2016).

19. Cheng, Y., Lu, S., Zhang, H., Varanasi, C. V. \& Liu, J. Synergistic effects from graphene and carbon nanotubes enable flexible and robust electrodes for highperformance supercapacitors. Nano Lett. 12, 4206-4211 (2012).

20. Li, L., Raji, A.-R. O. \& Tour, J. M. Graphene-wrapped $\mathrm{MnO}_{2}$-graphene nanoribbons as anode materials for high-performance lithium ion batteries. Adv. Mater. 25, 6298-6302 (2013).

21. Forse, A. C. et al. Direct observation of ion dynamics in supercapacitor electrodes using in situ diffusion NMR spectroscopy. Nat. Energy 2, 16216 (2017).

22. Lang, X., Hirata, A., Fujita, T. \& Chen, M. Nanoporous metal/oxide hybrid electrodes for electrochemical supercapacitors. Nat. Nanotechnol. 6, 232-236 (2011).

23. Kang, J. et al. Electroplated thick manganese oxide films with ultrahigh capacitance. Adv. Energy Mater. 3, 857-863 (2013)

24. Pang, S.-C., Anderson, M. A. \& Chapman, T. W. Novel electrode materials for thin-film ultracapacitors: comparison of electrochemical properties of sol-gelderived and electrodeposited manganese dioxide. J. Electrochem. Soc. 147, 444-450 (2000).

25. Broughton, J. N. \& Brett, M. J. Investigation of thin sputtered Mn films for electrochemical capacitors. Electrochim. Acta 49, 4439-4446 (2004).
26. Sun, Z., Firdoz, S., Yap, E. Y., Li, L. \& Lu, X. Hierarchically structured $\mathrm{MnO}_{2}$ nanowires supported on hollow $\mathrm{Ni}$ dendrites for high-performance supercapacitors. Nanoscale 5, 4379-4387 (2013).

27. Ho, C.-L. \& Wu, M.-S. Manganese oxide nanowires grown on ordered macroporous conductive nickel scaffold for high-performance supercapacitors. J. Phys. Chem. C. 115, 22068-22074 (2011).

28. Liu, Y., Zeng, Z., Bloom, B., Waldeck, D. H. \& Wei, J. Stable low-current electrodeposition of $\alpha-\mathrm{MnO}_{2}$ on superaligned electrospun carbon nanofibers for high-performance energy storage. Small 14, 1703237 (2018).

29. Chen, L.-F., Huang, Z.-H., Liang, H.-W., Guan, Q.-F. \& Yu, S.-H. Bacterialcellulose-derived carbon nanofiber@ $\mathrm{MnO}_{2}$ and nitrogen-doped carbon nanofiber electrode materials: an asymmetric supercapacitor with high energy and power density. Adv. Mater. 25, 4746-4752 (2013).

30. Wang, J.-G., Yang, Y., Huang, Z.-H. \& Kang, F. A high-performance asymmetric supercapacitor based on carbon and carbon- $\mathrm{MnO}_{2}$ nanofiber electrodes. Carbon N. Y. 61, 190-199 (2013).

31. Dong, $\mathrm{X}$. et al. $\mathrm{MnO}_{2}$-embedded-in-mesoporous-carbon-wall structure for use as electrochemical capacitors. J. Phys. Chem. B 110, 6015-6019 (2006).

32. Fischer, A. E., Pettigrew, K. A., Rolison, D. R., Stroud, R. M. \& Long, J. W. Incorporation of homogeneous, nanoscale $\mathrm{MnO}_{2}$ within ultraporous carbon structures via self-limiting electroless deposition: implications for electrochemical capacitors. Nano Lett. 7, 281-286 (2006).

33. Lytle, J. C. et al. The right kind of interior for multifunctional electrode architectures: carbon nanofoam papers with aperiodic submicrometre pore networks interconnected in 3D. Energy Environ. Sci. 4, 1913-1925 (2011).

34. Bates, F. S. \& Fredrickson, G. H. Block copolymer thermodynamics: theory and experiment. Annu. Rev. Phys. Chem. 41, 525-557 (1990).

35. Zhong, M. et al. Electrochemically active nitrogen-enriched nanocarbons with well-defined morphology synthesized by pyrolysis of self-assembled block copolymer. J. Am. Chem. Soc. 134, 14846-14857 (2012).

36. Qiang, Z., Xia, Y., Xia, X. \& Vogt, B. D. Generalized synthesis of a family of highly heteroatom-doped ordered mesoporous carbons. Chem. Mater. 29, 10178-10186 (2017).

37. Ruiz, R. et al. Density multiplication and improved lithography by directed block copolymer assembly. Science 321, 936-939 (2008).

38. Peinemann, K.-V., Abetz, V. \& Simon, P. F. W. Asymmetric superstructure formed in a block copolymer via phase separation. Nat. Mater. 6, 992-996 (2007).

39. Sai, H. et al. Hierarchical porous polymer scaffolds from block copolymers. Science 341, 530-534 (2013).

40. Song, Y. et al. Copolymer-templated synthesis of nitrogen-doped mesoporous carbons for enhanced adsorption of hexavalent chromium and uranium. ACS Appl. Nano Mater. 1, 2536-2543 (2018).

41. Yan, K. et al. Design and preparation of highly structure-controllable mesoporous carbons at the molecular level and their application as electrode materials for supercapacitors. J. Mater. Chem. A 3, 22781-22793 (2015).

42. Zhou Z., Liu T., Khan A. U., Liu G. Block copolymers based hierarchical porous carbon fibers. Sci. Adv. https://doi.org/10.1126/sciadv.aau6852 (2019).

43. Gomez, E. D., Das, J., Chakraborty, A. K., Pople, J. A. \& Balsara, N. P. Effect of cross-linking on the structure and thermodynamics of lamellar block copolymers. Macromolecules 39, 4848-4859 (2006).

44. Wilbur, J. D., Gomez, E. D., Ellsworth, M. W., Garetz, B. A. \& Balsara, N. P. Thermoreversible changes in aligned and cross-linked block copolymer melts studied by two color depolarized light scattering. Macromolecules $\mathbf{4 5}$, 7590-7598 (2012).

45. Lee, S.-W. et al. Structural changes in reduced graphene oxide upon $\mathrm{MnO}_{2}$ deposition by the redox reaction between carbon and permanganate ions. $J$. Phys. Chem. C. 118, 2834-2843 (2014).

46. Zhao, X. et al. Incorporation of manganese dioxide within ultraporous activated graphene for high-performance electrochemical capacitors. ACS Nano 6, 5404-5412 (2012).

47. Chigane, M. \& Ishikawa, M. Manganese oxide thin film preparation by potentiostatic electrolyses and electrochromism. J. Electrochem. Soc. 147, 2246-2251 (2000)

48. Xia, H., Wang, Y., Lin, J. \& Lu, L. Hydrothermal synthesis of $\mathrm{MnO}_{2} / \mathrm{CNT}$ nanocomposite with a CNT core/porous $\mathrm{MnO}_{2}$ sheath hierarchy architecture for supercapacitors. Nanoscale Res. Lett. 7, 33 (2012).

49. Zhu, S. et al. Structural directed growth of ultrathin parallel birnessite on $\beta$ $\mathrm{MnO}_{2}$ for high-performance asymmetric supercapacitors. ACS Nano 12, 1033-1042 (2018)

50. Zhai, T. et al. A new benchmark capacitance for supercapacitor anodes by mixed-valence sulfur-doped $\mathrm{V}_{6} \mathrm{O}_{13-\mathrm{x}}$. Adv. Mater. 26, 5869-5875 (2014).

51. Lei, C. et al. Activated carbon from phenolic resin with controlled mesoporosity for an electric double-layer capacitor (EDLC). J. Mater. Chem. A 1, 6037-6042 (2013).

52. Oyedotun, K. O. et al. Investigation of graphene oxide nanogel and carbon nanorods as electrode for electrochemical supercapacitor. Electrochim. Acta 245, 268-278 (2017). 
53. Hatzell, K. B. et al. Composite manganese oxide percolating networks as a suspension electrode for an asymmetric flow capacitor. ACS Appl. Mater. Interfaces 6, 8886-8893 (2014).

54. Zhang, F. et al. Multiscale pore network boosts capacitance of carbon electrodes for ultrafast charging. Nano Lett. 17, 3097-3104 (2017).

55. Zhang, X. et al. High performance asymmetric supercapacitor based on $\mathrm{MnO}_{2}$ electrode in ionic liquid electrolyte. J. Mater. Chem. A 1, 3706-3712 (2013).

56. Zhou, Z. \& Liu, G. Controlling the pore size of mesoporous carbon thin films through thermal and solvent annealing. Small 13, 1603107 (2017).

57. Yuan, Y. et al. The influence of large cations on the electrochemical properties of tunnel-structured metal oxides. Nat. Commun. 7, 13374 (2016).

58. Mai, L. et al. Fast ionic diffusion-enabled nanoflake electrode by spontaneous electrochemical pre-Intercalation for high-performance supercapacitor. Sci. Rep. 3, 1718 (2013).

59. Zhang, J. et al. Interior design of three-dimensional $\mathrm{CuO}$ ordered architectures with enhanced performance for supercapacitors. J. Mater. Chem. A 4, 6357-6367 (2016).

60. Shi, K. \& Giapis, K. P. Scalable fabrication of supercapacitors by nozzle-free electrospinning. ACS Appl. Energy Mater. 1, 296-300 (2018).

61. Shi, K. \& Zhitomirsky, I. Asymmetric supercapacitors based on activatedcarbon-coated carbon nanotubes. ChemElectroChem 2, 396-403 (2015).

\section{Acknowledgements}

This material is based upon work supported by the Air Force Office of Scientific Research under award number FA9550-17-1-0112 through the Young Investigator Program (YIP). Guoliang Liu acknowledges the American Chemical Society Petroleum Research Foundation for the Doctoral New Investigator (DNI) award. The authors acknowledge the use of electron microscopes in the Virginia Tech Institute for Critical Technology and Applied Science (ICTAS), and Dr. Xu Feng for assistance in the XPS analysis at the Surface Analysis Laboratory of Virginia Tech. The XPS is supported by the National Science Foundation under Grant No. CHE-1531834.

\section{Author contributions}

G.L. and T.L. designed all the experiments. T.L. performed the electrochemical and physical tests. Z.Z. participated in the synthesis of block copolymers and helped with the electrochemical and physical sorption tests. Y.G. collected the SEM images. D.G. synthesized the PAN homopolymers (the CF precursors). G.L. and T.L. wrote the paper with input from all authors.

\section{Additional information}

Supplementary Information accompanies this paper at https://doi.org/10.1038/s41467019-08644-w.

Competing interests: The authors declare no competing interests.

Reprints and permission information is available online at http://npg.nature.com/ reprintsandpermissions/

Journal peer review information Nature Communications thanks Christopher Arges and the other anonymous reviewers for their contribution to the peer review of this work. Peer reviewer reports are available.

Publisher's note: Springer Nature remains neutral with regard to jurisdictional claims in published maps and institutional affiliations.

(c) (i) Open Access This article is licensed under a Creative Commons Attribution 4.0 International License, which permits use, sharing, adaptation, distribution and reproduction in any medium or format, as long as you give appropriate credit to the original author(s) and the source, provide a link to the Creative Commons license, and indicate if changes were made. The images or other third party material in this article are included in the article's Creative Commons license, unless indicated otherwise in a credit line to the material. If material is not included in the article's Creative Commons license and your intended use is not permitted by statutory regulation or exceeds the permitted use, you will need to obtain permission directly from the copyright holder. To view a copy of this license, visit http://creativecommons.org/ licenses/by/4.0/.

(C) The Author(s) 2019 